\title{
Functional Characteristics of S-59 Photochemically Treated Platelet Concentrates Derived from Buffy Coats
}

\author{
D.J. van Rhenen ${ }^{a, b} \quad$ J. Vermeij ${ }^{a} \quad$ V. Mayaudon ${ }^{c} \quad$ C. Hind ${ }^{c} \quad$ L. Lin ${ }^{d}$ \\ L. Corash ${ }^{d, e}$
}

aBloodbank, Rotterdam, bDepartment of Haematology, University Hospital, Rotterdam, The Netherlands;

${ }^{c}$ Baxter R and D Europe SC, Nivelles, Belgium; 'Cerus Corporation, Concord, Calif., and

e Department of Laboratory Medicine, University of California, San Francisco, Calif., USA

\begin{abstract}
Background: A photochemical treatment (PCT) process for inactivation of infectious pathogens and leukocytes has been developed and evaluated using single-donor platelet concentrates. This study assessed the application of PCT to platelets prepared from pooled buffy coats. In this study, in vitro functional characteristics of PCT platelets were compared to control platelets prepared from pooled buffy coats using the approved plateletadditive solution T-Sol ${ }^{\circledR}$. Platelets in platelet PAS III additive solution without PCT were evaluated as well. PCT also included the use of a psoralen (S-59) reduction device (SRD). Materials and Methods: Four types of platelet concentrates were compared: (1) platelet concentrate in plasma/T-Sol; (2) platelet concentrate in plasma/PAS III; (3) platelet concentrate in plasma/PAS III, PCT, $9 \mathrm{~h}$ SRD and (4) platelet concentrate in plasma/ PAS III, PCT, $16 \mathrm{~h}$ SRD. PCT occurred on the day after whole-blood collection. In vitro assay parameters included: $\mathrm{pH}, \mathrm{pO}_{2}, \mathrm{pCO}_{2}, \mathrm{HCO}_{3}^{-}$, platelet count, mean platelet volume, plasma glucose, plasma lactate, total ATP, expression of p-selectin, hypotonic shock response and electron microscopy. Results: The results indicate that
\end{abstract}

\begin{tabular}{ll}
\hline KARGER & ( ) 2000 S. Karger AG, Basel \\
$0042-9007 / 00 / 0794-0206 \$ 17.50 / 0$ \\
$\begin{array}{l}\text { Fax +41 61 306 1234 } \\
\begin{array}{l}\text { E-Mail karger@karger.ch } \\
\text { www.karger.com }\end{array}\end{array}$ & $\begin{array}{l}\text { Accessible online at: } \\
\text { www.karger.com/journals/vox }\end{array}$
\end{tabular}

PCT is compatible with platelet concentrates prepared from pooled buffy coats for up to 7 days of storage. Conclusion: The PCT process resulted in acceptable in vitro platelet functional characteristics and is currently in clinical trials to evaluate the haemostatic efficacy of PCT platelets in thrombocytopenic patients requiring multiple platelet transfusions.

Copyright $\odot 2000$ S. Karger AG, Basel

\section{Introduction}

A photochemical treatment (PCT) process utilizing the psoralen (S-59) and long wavelength ultraviolet light (UVA, 320-400 nm) has been developed for treatment of platelet concentrates [1,2]. PCT with S-59 and UVA is a nucleic-acid-specific inactivation process with a broad spectrum of activity against bacteria, viruses and leukocytes. S-59 reversibly intercalates into helical regions of DNA and RNA. Upon illumination with UVA, S-59 reacts with pyrimidine bases to form covalent monoadducts and cross-links with nucleic acids. Bacteria, viruses or cells with genomes which have been modified by
Prof. D.J. van Rhenen, MD, PhD

Bloodbank Rotterdam

PO Box 23370

NL-3001 KJ Rotterdam (The Netherlands) 
S-59 are unable to replicate. Platelets are non-nucleated terminally differentiated cells which do not require nucleic acid transcription and translation for haemostatic function. Retention of in vitro platelet properties during storage does not require nucleic acid function [2]. This new PCT process provides an ex vivo method to increase the safety of platelet transfusion.

The efficacy of PCT has been demonstrated using single-donor platelet concentrates. High levels of a broad array of bacteria and viruses were inactivated in singledonor platelet concentrates $\left(3 \times 10^{11}-5 \times 10^{11}\right.$ platelets $)$ suspended in $300 \mathrm{ml}$ of $35 \%$ plasma and $65 \%$ platelet additive solution (PAS III) and exposed to $150 \mu \mathrm{M}$ S-59 and a $3 \mathrm{~J} / \mathrm{cm}^{2}$ treatment with UVA $[2,3]$. Contaminating leukocytes in platelet concentrates were inactivated by PCT at an S-59 dose level that is 1,500-fold lower than that used for bacterial and viral inactivation [4]. Following PCT, in vitro platelet function was adequately preserved during 7 days of storage $[2,3]$.

The PCT process results in photodegradation of S-59. After illumination and prior to transfusion, levels of residual S-59 and free photoproducts are reduced by treatment of the illuminated platelet concentrates with an integral S-59 reduction device (SRD). Platelets suspended in the container with the integral SRD were incubated with shaking in a temperature-controlled platelet incubator.

The purpose of the current study was to evaluate the in vitro characteristics of platelets obtained from pooled CPD buffy coats and submitted to the PCT process and two different SRD conditions. The PCT platelets were compared to control untreated platelets suspended in an approved platelet additive solution T-Sol and also to untreated platelets stored in PAS III. Three replicate experiments were performed each using a pool of 20 ABO-compatible buffy coats. The four arms of the study were: (1) first arm: platelet concentrate in plasma/T-Sol; (2) second arm: platelet concentrate in plasma/PAS III; (3) third arm: platelet concentrate in plasma/PAS III, PCT, $9 \mathrm{~h} \mathrm{SRD}$, and (4) fourth arm: platelet concentrate in plasma/PAS III, PCT, $16 \mathrm{~h}$ SRD.

Results from this study demonstrated that PCT is compatible with platelets prepared from pooled buffy coats. In vitro platelet function, assessed by hypotonic shock response, was not adversely affected during 7 days of storage following PCT under conditions that inactivated bacteria, viruses and leukocytes.

\section{Materials and Methods}

\section{Disposables - Wet Components}

The platelet additive solutions and the S-59 solution were provided in PL 2411 containers with tubing (a non-PVC plastic material made without a plasticizer; Baxter Healthcare Corporation, La Châtre, France). They were added to buffy coat platelets using a sterile connection device.

\begin{tabular}{ll}
\hline T-Sol ${ }^{\circledR}$ formulation & \\
Sodium chloride & $6.75 \mathrm{~g}$ \\
Sodium acetate, trihydrate & $4.08 \mathrm{~g}$ \\
Sodium citrate, dihydrate & $2.94 \mathrm{~g}$ \\
Water for injection & $1,000 \mathrm{ml}$ \\
pH 7.2 & \\
Volume & $300 \mathrm{ml}$ \\
\hline PAS III formulation & \\
Sodium chloride & $4.52 \mathrm{~g}$ \\
Sodium acetate, trihydrate & $4.42 \mathrm{~g}$ \\
Sodium citrate, dihydrate & $3.18 \mathrm{~g}$ \\
Dibasic sodium phosphate, anhydrous & $3.05 \mathrm{~g}$ \\
Monobasic sodium phosphate, dihydrate & $1.05 \mathrm{~g}$ \\
Water for injection & $1,000 \mathrm{ml}$ \\
pH 7.2 & \\
Volume & $280 \mathrm{ml}$ \\
\hline S-59 formulation & \\
Sodium chloride & $9.24 \mathrm{~g}$ \\
Psoralen S-59 & $1.01 \mathrm{~g}$ \\
Hydrochloric acid $1 N$ & for $\mathrm{pH}$ adjustment \\
Water for injection & $1,000 \mathrm{ml}$ \\
pH 5.0-6.0 & \\
Volume & $17.5 \mathrm{ml}$
\end{tabular}

\section{Disposables - Dry Components}

Whole blood was collected by using the Optipac ${ }^{\circledR}$ Triple bi-filled kit (Baxter Healthcare). The kit consists of a primary 'bottom and top' container filled with $70 \mathrm{ml}$ of CPD anti-coagulant solution, a secondary conventional container filled with $110 \mathrm{ml}$ of SAG-M solution and an empty transfer container. Packs are made of PL 2209 plastic (a polyvinyl chloride (PVC) with a non-DEHP plasticizer). A 600-ml transfer pack with 8 leads was used to pool buffy coats (Baxter Healthcare). The Optidock buffy coat leukodepletion set consists of a Pall Autostop ${ }^{\circledR}$ buffy coat filter, specifically designed to remove leukocytes in the production of platelets from buffy coats, and a 1.3litre PL 2410 plastic container. The platelet illumination container was a 1-litre PL 2410 plastic container (Baxter Healthcare). The platelet storage container was a 1.3-litre PL 2410 plastic container (Baxter Healthcare).

\section{S-59 Removal Device}

The SRD consists of approximately $2.5 \mathrm{~g}$ of polystyrene beads enclosed in a polyester mesh pouch with a 1-litre PL 2410 plastic container.

\section{Equipment}

The Optipress II ${ }^{\circledR}$ (Baxter Healthcare Corporation, Nivelles, Belgium) was used for separation of the blood collected and centrifuged 
in Optipac. The UVA illumination device (code No. 4R4440, Baxter Healthcare Corp., Deerfield, Ill., USA) mounted on a reciprocal platelet shaker (Helmer Labs, Noblesville, Ind., USA) was used for illumination with a wavelenght of $320-400 \mathrm{~nm}$. The UVA device is air-cooled. The output of this device was approximately $15-20 \mathrm{~mW} /$ $\mathrm{cm}^{2}$ permitting delivery of $3 \mathrm{~J} / \mathrm{cm}^{2}$ in approximately $3-4 \mathrm{~min}$.

\section{Blood Processing}

Preparation of Buffy Coats

Blood units of $500 \mathrm{ml} \pm 10 \%$ were collected from volunteer donors in $70 \mathrm{ml}$ CPD anticoagulant solution using triple Optipac (Baxter Healthcare). Selection of donors and the blood donation procedure were based on local standard practices. The whole blood units were kept overnight $(16-20 \mathrm{~h})$ at room temperature $\left(20 \pm 2{ }^{\circ} \mathrm{C}\right)$. High-speed centrifugation $(4,650 \mathrm{~g}, 10 \mathrm{~min})$ was applied to separate cellular components from plasma (Beckman Instr. Inc., Fullerton, Calif., USA). Buffy coats of $55 \pm 5 \mathrm{ml}$ were separated from plasma and packed red cells using the Optipress II standard procedure.

\section{Preparation of Study Platelet Concentrates}

Preparation of Pooled Buffy Coats. Using a sterile docking device SCD312 (Terumo, Japan), a pool of 20 ABO-compatible buffy coats was made in a 1.3-litre PL 2410 plastic container. After thorough mixing, the pool was separated into equal volumes in four $600-\mathrm{ml}$ transfer packs. To one container the standard volume of approximately $300 \mathrm{ml}$ T-Sol was added. To each of the three remaining containers $280 \mathrm{ml}$ PAS III was added to reduce the plasma concentration to $30-45 \%$ for optimal PCT performance.

Preparation of Leukofiltered Platelet Concentrates. Using a sterile docking device SCD312, a buffy coat leukodepletion set, comprised of an Autostop buffy coat filter and a 1.3-litre PL 2410 plastic container, was connected to each of the 5 buffy coat pools. Low-speed centrifugation ( $655 \mathrm{~g}, 5 \mathrm{~min})$ was applied to the bag assembly to separate the platelet-rich plasma diluted with either T-Sol or PAS III from the red cells. After centrifugation, the platelet-rich plasma diluted with T-Sol or PAS III was expressed into the PL 2410 bag through the Autostop filter.

Preparation of Untreated Platelet Concentrates (1st and 2nd Arms). The resultant leukoreduced platelet concentrate suspended in T-Sol (1st arm) and that suspended in PAS III (2nd arm) were not treated with PCT and were used as controls. They were stored on a flat-bed shaker (50-60 cycles/min) for up to 7 days at $20-24^{\circ} \mathrm{C}$. Day 0 was designated as the day of collection.

Preparation of PCT Platelet Concentrates (3rd and 4th Arms). The PCT proceeded immediately after platelet processing. The process is described in the flow chart (fig. 1).

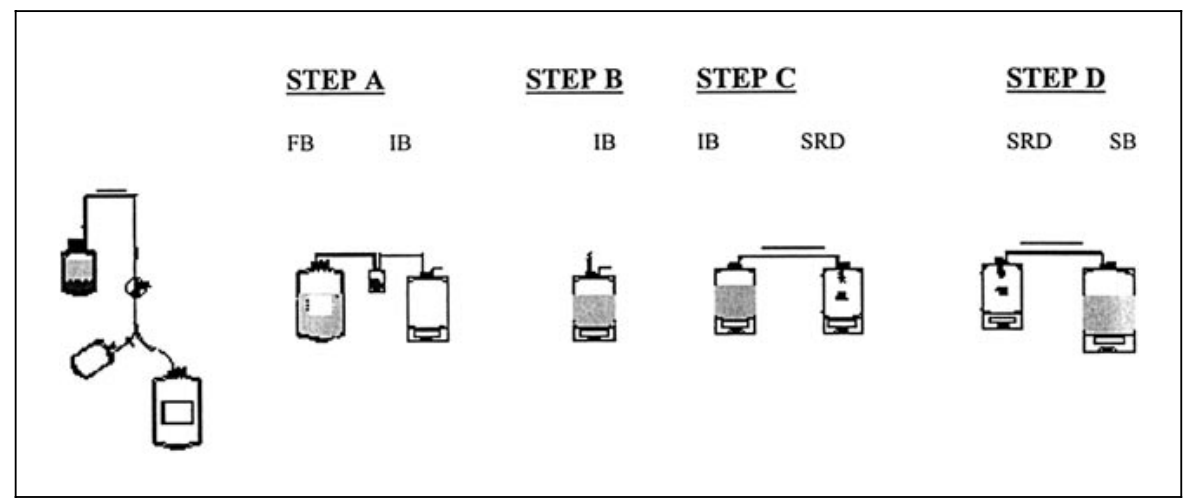

Fig. 1. Preparation of $P C T B C-P C . F B=$ Filtration bag; $I B=$ illumination bag; $S R D=S-59$ removal device; $S B=$ storage bag.

Step A: Transfer of the Platelet Concentrate into the Illumination Container. Using a sterile docking device SCD312, the platelet container, the S-59 container and the illumination container were sterileconnected in series. The leukoreduced platelet concentrate in plasma/PAS III was passed through the S-59 solution into the PL 2410 illumination container. The air was expressed out of the illumination container. The illumination container containing the platelet concentrate and S-59 was then separated from the S-59 container and the platelet container by heat seal.

Step B: Illumination. Platelet mixture with added S-59 in the PL 2410 illumination container was placed in the UVA illumination device. The platelet mixture was exposed to a $3 \mathrm{~J} / \mathrm{cm}^{2}$ treatment with UVA with agitation ( 60 cycles/min).
Step C: Transfer into the $S R D$. After UVA illumination, the illumination container was sterile-connected to an SRD. The platelet mixture was transferred into the SRD. The air was expressed out of the SRD container. After separating the SRD from the illumination bag by heat seal, the treated platelets were stored with agitation at 20$24^{\circ} \mathrm{C}$ for $9 \mathrm{~h}$ (3rd arm), or for $16 \mathrm{~h}$ (4th arm) in the SRD.

Step D: Platelet Storage. After the incubation period in an SRD, the platelet mixture was transferred into a 1.3-litre PL 2410 plastic storage container for continued storage for up to 7 days from collection with agitation on a flat-bed shaker (50-60 cycles/min) at $20-24{ }^{\circ} \mathrm{C}$ (day 0 is day of collection). 


\section{In vitro Platelet Assays}

Platelet aliquots were drawn under sterile conditions on storage day 1 (before addition of S-59 for arms 3 and 4), 2, 3, 5 and 7.

Haematological parameters were measured electronically (Cell Dyn 3500, Abbott Laboratories, Chicago, Ill., USA) and leukocyte contamination was measured microscopically in a Nageotte chamber. Blood gases and bicarbonate were analysed with a $238 \mathrm{pH}$ Blood Gas System (Ciba Corning, UK).

Glucose concentration and lactate concentration were measured in a Dimension Chemistry Analyzer (Dupont, Wilmington, Del., USA). ATP was measured with a chemiluminescence method in a Lumicount counter (Packard Corp., Groningen, NL).

For estimation of platelet activation, GMP140 expression (pselectin) by flow cytometry was measured by two-color labelling using a FACScan (Becton \& Dickinson, San Jose, Calif., USA). FITC labelling of platelets was performed with anti-CD42. GMP expression was determined using anti-CD62 (PE). Both reagents are manufactured by Becton \& Dickinson. The assay method was as follows: platelets were fixed in $1 \%$ paraformaldehyde and directly labelled with anti-CD42 (FITC) and anti-CD62 (PE); the scatter gates were set on the platelet population fraction; laser excitation was at $488 \mathrm{~nm}$.

Hypotonic shock response was measured as described by Holm et al. [5]. Measurements were performed on a spectrophotometer (LKB, Ultrospect II, Cambridge, UK).

The samples for electron microscopy (EM) were prepared according to the method described by Klinger and Kluter [6]. For test platelet concentrates, samples were taken on day 1 after UVA illumination and on days 2 and 5 of storage. For control platelet concentrates, samples were taken in parallel with the test platelets on days 1, 2 and 5. Briefly, all platelet samples were embedded in Araldite resin, then polymerized in fresh resin at $60-70^{\circ} \mathrm{C}$ for up to $48 \mathrm{~h}$. From the subsequent resin blocks produced, semi- and ultra-thin sections were cut and collected on nickel grids. These were stained using saturated alcoholic uranyl acetate and lead citrate, examined and images recorded using transmission EM. A minimum of 4 images from each sample were analyzed for platelet morphology using a final magnification of $\times 6,500$. Platelets with abnormal morphologic ultrastructure characterized by extreme swelling and loss of cytoplasmic organelles were enumerated as 'lysed platelets'. Samples were analysed blind-coded.

Lysed platelets can be distinguished from normal platelets, and are characterised by extreme swelling and pallor of the cytoplasmic contents due to the disintegration and subsequent loss of cytoplasmic proteins and organelles such as mitochondria, the open canalicular system as well as the microtubules which maintain their normal discoid shape and their pseudopods.

\section{Statistical Analysis}

In vitro data were expressed as the arithmetic mean \pm SD. All data from day 2 to day 7 were analysed using analysis of variance (ANOVA) to determine significant differences between the four groups of platelet concentrate treatments. The difference was considered statistically different with $\mathrm{p}<0.05$. The analysis was performed using Statistica (melease 5.1 for Windows (copyright Statsoft, Inc., 1984-1996).
Table 1. Platelet product characteristics $(n=3)$ : comparison between T-Sol and PAS III ${ }^{1}$

\begin{tabular}{lllll}
\hline Study arm & $\begin{array}{l}\text { Platelet } \\
\text { additive } \\
\text { solution }\end{array}$ & $\begin{array}{l}\text { Unit } \\
\text { volume } \\
\mathrm{ml}\end{array}$ & $\begin{array}{l}\text { Platelet } \\
\text { dose } \\
\times 10^{11}\end{array}$ & $\begin{array}{l}\text { Plasma } \\
\text { content } \\
\%\end{array}$ \\
\hline 1 & T-Sol & $357 \pm 5$ & $4.1 \pm 0.3$ & $32 \pm 0.6$ \\
2 & PAS III & $325 \pm 4$ & $4.3 \pm 0.2$ & $34 \pm 1.0$ \\
3 & PAS III & $327 \pm 2^{2}$ & $4.1 \pm 0.1$ & $34 \pm 0.6$ \\
4 & PAS III & $325 \pm 3^{2}$ & $4.2 \pm 0.4$ & $34 \pm 0.6$ \\
$\begin{array}{l}\text { PCT range } \\
\text { requirement }\end{array}$ & & $315-410^{3}$ & $2.5-5.0$ & $30-45$ \\
\hline
\end{tabular}

1 Measured on day 1.

2 Volume of platelet concentrates before addition of $17.5 \mathrm{ml}$ of S-59.

3 Volume range during UVA illumination.

\section{Results}

\section{Platelet Product Characteristics}

The unit volume, platelet yield, and plasma content of platelet concentrates prepared from pooled buffy coats using $300 \mathrm{ml}$ T-Sol were determined (table 1). The platelet concentrates prepared using the same procedures but with $280 \mathrm{ml}$ of PAS III had characteristics similar to platelet concentrates prepared in T-Sol. All platelet products in PAS III met the photochemical treatment target range requirements in unit volume, platelet yield and percent plasma for PCT (table 1).

\section{In vitro Platelet Characteristics}

Following PCT, platelets were compared to untreated control platelets during 7 days of storage. The $\mathrm{pH}$ was stable until day 3 and fell in all groups upon further storage (table 2). There were statistically significant differences among study groups $(\mathrm{p}<0.05)$. However, the $\mathrm{pH}$ was well maintained. At day 7, the $\mathrm{pH}$ in all groups was greater than 6.8 .

The $\mathrm{O}_{2}$ consumption increased from day 1 to day 3 (table 3) and then slowly decreased in all products. A difference was observed between the PCT products and controls $(\mathrm{p}<0.05)$. The level of $\mathrm{pCO}_{2}$ dropped consistently during storage in the PCT products and fell to $25-26 \mathrm{~mm}$ $\mathrm{Hg}$ on day 7 (table 4). In both control groups the level of $\mathrm{pCO}_{2}$ stabilized after day 2 . The concentration of $\mathrm{HCO}_{3}^{-}$ decreased in all groups during storage but more profoundly in the PCT groups at day $7(\mathrm{p}<0.05)($ table 5). On day 7 all groups still had greater than $4 \mathrm{~m} M \mathrm{HCO}_{3}^{-}$remaining to provide buffering of the platelet concentrates. 
Table 2. Mean measurements of $\mathrm{pH}$ at $37^{\circ} \mathrm{C}$ in the 4 groups $(\mathrm{n}=3$, $\overline{\mathrm{X}} \pm \mathrm{SD})$

\begin{tabular}{lllll}
\hline Day & T-Sol & PAS III & \multicolumn{2}{l}{ PCT-SRD } \\
\cline { 3 - 5 } & & & $9 \mathrm{~h}$ & $16 \mathrm{~h}$ \\
\hline 1 & $7.00 \pm 0.01$ & $7.05 \pm 0.01^{1}$ & $7.06 \pm 0.01^{1}$ & $7.06 \pm 0.00^{1}$ \\
2 & $7.02 \pm 0.01$ & $7.05 \pm 0.00^{1}$ & $7.01 \pm 0.00^{1,2}$ & $7.01 \pm 0.01^{1,2}$ \\
3 & $7.02 \pm 0.01$ & $7.03 \pm 0.01^{1}$ & $7.00 \pm 0.00^{1,2}$ & $7.00 \pm 0.01^{1,2}$ \\
5 & $6.96 \pm 0.01$ & $6.98 \pm 0.01$ & $6.93 \pm 0.01^{1,2}$ & $6.95 \pm 0.01^{2}$ \\
7 & $6.88 \pm 0.01$ & $6.90 \pm 0.02$ & $6.83 \pm 0.02^{1,2}$ & $6.85 \pm 0.02^{2}$ \\
\hline
\end{tabular}

$\mathrm{p}<0.05$ compared to T-Sol control.

$\mathrm{p}<0.05$ compared to PAS III control.
Table 5. Mean measurements of bicarbonate $(\mathrm{mM})$ at $37^{\circ} \mathrm{C}$ in the 4 groups $(\mathrm{n}=3, \overline{\mathrm{X}} \pm \mathrm{SD})$

\begin{tabular}{lllll}
\hline Day & T-Sol & PAS III & \multicolumn{2}{l}{ PCT-SRD } \\
\cline { 3 - 5 } & & & $9 \mathrm{~h}$ & $16 \mathrm{~h}$ \\
\hline 1 & $8.5 \pm 0.2$ & $8.9 \pm 0.2$ & $8.9 \pm 0.3$ & $8.9 \pm 0.3$ \\
2 & $8.1 \pm 0.2$ & $8.5 \pm 0.2$ & $7.7 \pm 0.2^{2}$ & $7.8 \pm 0.1^{2}$ \\
3 & $8.1 \pm 0.2$ & $8.2 \pm 0.1$ & $7.0 \pm 0.1^{1,2}$ & $7.2 \pm 0.2^{1,2}$ \\
5 & $7.3 \pm 0.2$ & $7.0 \pm 0.2$ & $5.6 \pm 0.1^{1,2}$ & $5.7 \pm 0.4^{1,2}$ \\
7 & $6.2 \pm 0.2$ & $5.8 \pm 0.4$ & $4.3 \pm 0.2^{1,2}$ & $4.3 \pm 0.5^{1,2}$ \\
\hline
\end{tabular}

$\mathrm{p}<0.05$ compared to T-Sol control.

$\mathrm{p}<0.05$ compared to PAS III control.
Table 3. Mean measurements of $\mathrm{pO}_{2}(\mathrm{~mm} \mathrm{Hg})$ at $37^{\circ} \mathrm{C}$ in the 4 groups $(\mathrm{n}=\overline{\mathrm{X}} \pm \mathrm{SD})$

\begin{tabular}{lllll}
\hline Day & T-Sol & PAS III & \multicolumn{2}{l}{ PCT-SRD } \\
\cline { 3 - 5 } & & & \multicolumn{2}{l}{$16 \mathrm{~h}$} \\
\hline 1 & $86.7 \pm 5.5$ & $87.3 \pm 5.7$ & $107.0 \pm 11.3^{1,2}$ & $108.0 \pm 1.7^{1,2}$ \\
2 & $58.0 \pm 13.0$ & $58.0 \pm 13.0$ & $72.3 \pm 1.5$ & $79.0 \pm 8.0$ \\
3 & $50.7 \pm 6.1$ & $48.7 \pm 5.7$ & $65.0 \pm 4.6^{1,2}$ & $68.7 \pm 8.0^{1,2}$ \\
5 & $57.3 \pm 7.2$ & $56.0 \pm 7.5$ & $74.7 \pm 3.1^{1,2}$ & $78.7 \pm 9.3^{1,2}$ \\
7 & $58.7 \pm 5.9$ & $60.3 \pm 9.1$ & $82.7 \pm 4.7$ & $93.7 \pm 6.7$ \\
\hline 1 & $\mathrm{p}<0.05$ compared to T-Sol control. & \\
2 & $\mathrm{p}<0.05$ compared to PAS III control. \\
\hline
\end{tabular}

Table 4. Mean measurements of $\mathrm{pCO}_{2}(\mathrm{~mm} \mathrm{Hg})$ at $37^{\circ} \mathrm{C}$ in the 4 groups $(n=3, \bar{X} \pm S D)$

\begin{tabular}{lllll}
\hline Day & T-Sol & PAS III & \multicolumn{2}{l}{ PCT-SRD } \\
\cline { 3 - 5 } & & & $9 \mathrm{~h}$ & $16 \mathrm{~h}$ \\
\hline 1 & $33.7 \pm 0.6$ & $32.0 \pm 1.0$ & $31.7 \pm 1.5$ & $31.7 \pm 0.6$ \\
2 & $31.7 \pm 1.2$ & $30.7 \pm 0.6$ & $30.3 \pm 0.6$ & $31.3 \pm 0.6$ \\
3 & $31.7 \pm 1.2$ & $31.0 \pm 1.0$ & $28.7 \pm 0.6^{1,2}$ & $28.7 \pm 0.6^{1,2}$ \\
5 & $32.0 \pm 1.0$ & $30.0 \pm 1.0$ & $27.3 \pm 0.6^{1,2}$ & $26.0 \pm 1.7^{1,2}$ \\
7 & $33.7 \pm 1.2$ & $30.0 \pm 1.0$ & $25.7 \pm 0.6^{1,2}$ & $24.7 \pm 1.5^{1,2}$ \\
\hline
\end{tabular}

$\mathrm{p}<0.05$ compared to T-Sol control.

$\mathrm{p}<0.05$ compared to PAS III control.
Table 6. Mean measurements of volume $\mathrm{ml}$ in the 4 groups $(\mathrm{n}=3$, $\overline{\mathrm{X}} \pm \mathrm{SD})$

\begin{tabular}{lllll}
\hline Day & T-Sol & PAS III & \multicolumn{2}{l}{ PCT-SRD } \\
\cline { 3 - 5 } & & & $9 \mathrm{~h}$ & $16 \mathrm{~h}$ \\
\hline 1 & $357 \pm 5$ & $325 \pm 4^{1}$ & $327 \pm 2^{1}$ & $325 \pm 3^{1}$ \\
2 & $349 \pm 5$ & $316 \pm 3^{1}$ & $313 \pm 2^{1}$ & $312 \pm 5^{1}$ \\
3 & $344 \pm 5$ & $311 \pm 2^{1}$ & $307 \pm 2^{1}$ & $306 \pm 4^{1}$ \\
5 & $342 \pm 5$ & $310 \pm 2^{1}$ & $306 \pm 2^{1}$ & $305 \pm 5^{1}$ \\
7 & $337 \pm 5$ & $305 \pm 3^{1}$ & $301 \pm 2^{1}$ & $300 \pm 5^{1}$ \\
\hline
\end{tabular}

$\mathrm{p}<0.05$ compared to T-Sol control.

Table 7. Mean measurements of platelet counts $\times 10^{9} / 1$ in the 4 groups $(n=3, \bar{X} \pm S D)$

\begin{tabular}{lllll}
\hline Day & T-Sol & PAS III & \multicolumn{2}{l}{ PCT-SRD } \\
\cline { 3 - 5 } & & & $9 \mathrm{~h}$ & $16 \mathrm{~h}$ \\
\hline 1 & $1,159 \pm 63$ & $1,326 \pm 76$ & $1,267 \pm 24$ & $1,291 \pm 119$ \\
2 & $1,163 \pm 78$ & $1,283 \pm 61$ & $1,212 \pm 42$ & $1,208 \pm 85$ \\
3 & $1,144 \pm 31$ & $1,264 \pm 45$ & $1,182 \pm 28$ & $1,182 \pm 100$ \\
5 & $1,157 \pm 39$ & $1,267 \pm 62$ & $1,171 \pm 26^{1,2}$ & $1,154 \pm 81^{1,2}$ \\
7 & $1,149 \pm 64$ & $1,257 \pm 65$ & $1,155 \pm 26^{1}$ & $1,143 \pm 971,2$ \\
\hline
\end{tabular}

$\mathrm{p}<0.05$ compared to T-Sol control.

$\mathrm{p}<0.05$ compared to PAS III control. 
Table 8. Mean measurements of plasma glucose in $\mathrm{mmol} / \mathrm{l}$ in the 4 groups $(\mathrm{n}=3, \overline{\mathrm{X}} \pm \mathrm{SD})$

\begin{tabular}{lllll}
\hline Day & T-Sol & PAS III & \multicolumn{2}{l}{ PCT-SRD } \\
\cline { 3 - 5 } & & & $9 \mathrm{~h}$ & $16 \mathrm{~h}$ \\
\hline 1 & $7.1 \pm 0.2$ & $7.7 \pm 0.05^{1}$ & $7.6 \pm 0.2^{1}$ & $7.5 \pm 0.2^{1}$ \\
2 & $6.7 \pm 0.05$ & $7.2 \pm 0.05^{1}$ & $6.7 \pm 0.1^{2}$ & $6.9 \pm 0.2^{1,2}$ \\
5 & $5.0 \pm 1.0$ & $4.8 \pm 1.0$ & $3.9 \pm 0.2^{1}$ & $4.1 \pm 0.2^{1}$ \\
7 & $3.0 \pm 0.1$ & $2.2 \pm 0.2^{1}$ & $1.7 \pm 0.1^{1,2}$ & $2.0 \pm 0.1^{1}$ \\
\hline
\end{tabular}

$\mathrm{p}<0.05$ compared to T-Sol control.

$\mathrm{p}<0.05$ compared to PAS III control.

Table 9. Mean measurements of plasma lactate in $\mathrm{mmol} / \mathrm{l}$ in the 4 groups $(n=3, \bar{X} \pm S D)$

\begin{tabular}{lrccc}
\hline Day & \multicolumn{1}{l}{ T-Sol } & PAS III & \multicolumn{2}{c}{ PCT-SRD } \\
\cline { 3 - 4 } & & & $9 \mathrm{~h}$ & $16 \mathrm{~h}$ \\
\hline 1 & $4.0 \pm 0.1$ & $4.1 \pm 0.2$ & $4.0 \pm 0.2$ & $4.2 \pm 0.7$ \\
2 & $4.6 \pm 0.3$ & $5.0 \pm 0.2$ & $4.6 \pm 0.2$ & $4.6 \pm 0.4$ \\
5 & $8.3 \pm 0.5$ & $9.9 \pm 1.7$ & $10.4 \pm 0.7$ & $9.9 \pm 0.6$ \\
7 & $11.1 \pm 0.1$ & $13.5 \pm 0.3^{1}$ & $13.1 \pm 0.4^{1}$ & $13.0 \pm 0.8^{1}$ \\
\hline
\end{tabular}

$\mathrm{p}<0.05$ compared to T-Sol control.

Table 10. Mean measurement of total ATP $\mu \mathrm{mol} / 10^{11}$ platelets in the 4 groups $(n=6, \bar{X} \pm S D)$

\begin{tabular}{lllll}
\hline Day & T-Sol & PAS III & \multicolumn{2}{l}{ PCT-SRD } \\
\cline { 4 - 5 } & & & $9 \mathrm{~h}$ & $16 \mathrm{~h}$ \\
\hline 1 & $2.9 \pm 0.2$ & n.d. & n.d. & n.d. \\
2 & $2.7 \pm 0.4$ & n.d. & n.d. & $2.7 \pm 0.5$ \\
5 & $3.5 \pm 0.3$ & n.d. & n.d. & $3.5 \pm 0.3$ \\
7 & $3.1 \pm 1.1$ & n.d. & n.d. & $3.1 \pm 1.1$ \\
\hline
\end{tabular}

n.d. = Not done. There were no statistically significant differences between groups.
An overall reduction in platelet content of approximately 15\% (3rd arm) and 19\% (4th arm) after 7 days was seen in the PCT products in comparison with a reduction of $5 \%(1 \mathrm{st} \mathrm{arm})$ and $12 \%(2 \mathrm{nd}$ arm) in the control products $(\mathrm{p}<0.05)$. This reduction was primarily due to the volume of samples withdrawn for various function analyses (table 6). A larger volume loss was observed during PCT processing which involved transfers of platelets from the illumination container to the SRD container and then to the storage container. No difference was seen in platelet counts per liter between SRD exposures of 9 and $16 \mathrm{~h}$ (table 7).

The residual leukocytes after filtration ranged from $<0.1 \times 10^{6} / 1$ to $0.3 \times 10^{6} / 1$ in all four study groups. No statistically significant differences were detected among study groups. These products were considered leukoreduced.

Mean platelet volume increased during storage in both the PCT and control groups. However, there were no statistically significant differences between the study groups.

Biochemical parameters showed a fall in glucose in all groups during storage but on day 7 a sufficient amount of glucose was available for metabolism (table 8). No difference was seen between the groups on day 5. Lactate levels increased as expected in all four groups during storage (table 9). There were statistically significant differences between the T-Sol control group and the groups in PAS III at day $7(\mathrm{p}<0.05)$. Analysis of total ATP showed that even at day 7 sufficient ATP was available (table 10). There were no statistically significant differences between the $T$ Sol control group and the PCT-SRD 16-hour treated group.

Activation marker GMP-140 showed an increase in the proportion of activated platelets in both the control and the PCT group during storage (table 11) with a higher percentage of activated platelets in the PCT group $(\mathrm{p}<$ $0.05)$.

Hypotonic shock response was stable from day 1 to day 7 during storage without any difference between the groups (table 12). Both test and control products demonstrated preservation of the swirling phenomenon on all days through day 7.

\section{Electron Microscopic Evaluation of Platelets}

For the PCT study arms, day 1 analysis was performed on platelet samples withdrawn following UVA illumination before SRD exposure. On day 2, platelet samples were withdrawn following PCT including SRD exposure. Platelet lysis increased during storage in all groups and

Vox Sang 2000;79:206-214 211
Functional Characteristics of S-59

Photochemically Treated Platelet

Concentrates 
treatment with long wave length ultraviolet light (UVA $320-400 \mathrm{~nm}$ ). Under these conditions, high levels of viruses, bacteria and leukocytes were inactivated [2-4]. This study assessed the application of PCT to platelets prepared from pooled buffy coats.

Preliminary studies suggested the optimal PCT conditions were plasma concentration within the critical limits of $30-45 \%$ of the total volume. These conditions also are compatible with the pooled buffy coat method of platelet preparation utilizing T-Sol, a platelet storage medium similar to PAS III. Prior to a clinical transfusion study with PCT platelet concentrates, we conducted an in vitro study to evaluate the characteristics of pooled buffy coat concentrates in plasma and PAS III subjected to PCT and 7 days of storage. These studies were also used to develop standardized procedures for production and quality control of PCT platelet concentrates.

The in vitro platelet function studies showed no evidence of metabolic deterioration of platelets after PCT and subsequent storage for up to 7 days. The $\mathrm{pH}\left(37^{\circ} \mathrm{C}\right)$ of PCT platelets was maintained above 6.8 throughout the 7 days of storage. PCT did not stimulate glycolysis. Similar levels of glucose remained on day 7 for the control group with PAS III and the PCT groups. Consequently, lactate levels of PCT platelets on day 7 were comparable to control platelets in PAS III. At day 7, a sufficient amount of glucose was still available for metabolism using the current preparation methods (residual plasma of $34 \pm 1 \%$ ). No difference was detected in total ATP at day 7 among the various study groups, confirming that platelet metabolism was conserved. Although other studies have shown an effect of UVA light on cellular mitochondrial membrane potential [13], PCT did not affect total platelet ATP content up to 7 days of storage indicating that platelet mitochondrial function was conserved. Maintenance of the ATP level correlates with platelet viability [14]. Furthermore, the hypotonic shock response analysis was consistent with preservation of platelet energy metabolism.

Due to repeated sampling for platelet analysis and several transfers between platelet containers during PCT processing, the platelet content in both PCT groups was lower compared to the control groups. The difference in platelet content may have accounted for some of the differences in $\mathrm{pO}_{2}, \mathrm{pCO}_{2}$, and $\mathrm{HCO}_{3}^{-}$between the control groups and the PCT groups. The activation marker GMP-140 (pselectin) showed a greater increase during storage in the PCT groups. However, it is not clear from the literature whether in vitro p-selectin expression correlates with in vivo viability. Shortened survival of activated platelets after transfusion has been reported in studies on platelet apheresis [15-17]. On the other hand, it was also reported that expression of the p-selectin epitope recognized by the CD62 antibody does not correlate with in vivo platelet recovery [18]. The proportion of lysed platelets, as assessed by electron microscopy, on day 5 in both photochemically treated groups was higher than that of the control arms. It is presently unknown whether there was random loss of platelets or whether older platelets were more susceptible to lysis. The higher p-selectin levels, subtle changes in respiratory activity, and a higher proportion of platelets with altered morphology may represent an effect of PCT on small numbers of older platelets [19].

Prior studies with 5-day-old single-donor platelets have demonstrated a small decrease in post-transfusion recovery and life span, but within an acceptable range for therapeutic support of thrombocytopenic patients [20]. Recently, studies in patients have demonstrated that PCT platelets gave an adequate platelet count increment, corrected prolonged bleeding times, and the interval to the next platelet transfuison was comparable to standard platelets [21].

The current BC-PC preparation process with a limited content of plasma $(34 \pm 1 \%)$ allows good maintenance of in vitro platelet function. A method was developed to control the proportion of plasma in BC-PC preparations for PCT by using the volume of the residual pooled buffy coat, the haematocrit of the residual pooled buffy coat and the volume of the buffy coat PC. The production process, which requires extra hands-on time, can be organized in such a way in the blood bank that a full time availability to the patients in hospital can be maintained.

In conclusion, the results from the in vitro studies indicate that PCT is compatible with platelet concentrates prepared from pooled buffy coats for up to 7 days of storage. These PCT pooled buffy coat platelets are currently in a clinical trial to evaluate the post-transfusion platelet count increment and the haemostatic efficacy in thrombocytopenic patients.

\section{Acknowledgment}

The authors wish to thank Dr. Don Buchholz of Baxter Healthcare Corporation and Dr. George Cimino and John Tessman of Cerus Corporation for critical review of the manuscript. 


\section{References}

1 Wollowitz S, Isaacs ST, Rapoport H, Spielmann HP: Compounds for the photodecontamination of pathogens in blood. US Patent No 5,399,719, March 21, 1995.

2 Lin L, Cook DN, Wiesehahn GP, Alfonso R, Behrman B, Cimino GD, Corten L, Damonte PB, Dikeman R, Dupuis K, Fang YM, Hanson CV, Hearst JE, Lin CY, Londe HF, Metchette $\mathrm{K}$, Nerio AT, Pu JT, Reames AA, Rheinschmidt M, Tessman J, Isaacs ST, Wollowitz S, Corash L: Photochemical inactivation of viruses and bacteria in human platelet concentrates using a novel psoralen and long wavelength ultraviolet light. Transfusion 1997;37: 423.

3 Lin L, Alfonso R, Behrman B, Corten L, Damonte PB, Dikeman R, Dupuis K, Hei D, Lin CY, Londe HF, Metchette K, Phan T, Reames AA, Rheinschmidt M, Savoor A, Tessman J, Corash L: Photochemical treatment of platelet concentrates with a novel psoralen and UVA to enhance the safety of platelet transfusions. Infusionsther Transfusionsmed 1998;25:39-48.

4 Grass JA, Hei DJ, Metchette K, Cimino GD, Wiesehahn GP, Corash L, Lin L: Inactivation of leukocytes in platelet concentrates by photochemical treatment with psoralen plus UVA. Blood 1998;91:2180.

5 Holme S, Heaton WA, Courtright M: Improved in vivo and in vitro viability of platelet concentrates stored for seven days in a platelet additive solution. Br J Haematol 1987;66:233238 .

6 Klinger MHF, Kluter H: Morphological changes in thrombocytes during blood bank storage. An ultrastructural morphometric study. Ann Anat 1993;175:163.
7 Van Rhenen DJ, Vermeij J, Kappers-Klunne MC, Payrat JM: Evaluation of a new citrateacetate- $\mathrm{NaCl}$ platelet additive solution for the storage of white cell reduced platelet concentrates obtained from half strength CPD pooled buffy coats. Transfusion 1995;35:50-53.

8 Eriksson L, Kristensen J, Olsson K, Bring J, Högman CF: Evaluation of platelet function using the in vitro bleeding time and corrected count increment of transfused platelets. Comparison between platelet concentrates derived from pooled buffy coats and apheresis. Vox Sang 1996;70:69-75.

9 Blajchman MA, Ali AM, Richardson HL: Bacterial contamination of cellular blood components. Vox Sang 1994;67 S3:25-33.

10 Chiu EKW, Yuen KY, Lie AKW, Liang R, Lau YL, Lee ACW, Kwong YL, Wong S, Ng MH, Chan TK: A prospective study of symptomatic bacteremia following platelet transfusion and of its management. Transfusion 1994;34:950 954.

11 Högman CF: Adverse effects: Bacterial contamination (including shelf-life). A brief review of bacterial contamination of blood components. Vox Sang 1996;70(suppl 3):78-82.

12 Lin L, Londe H, Janda JM, Hanson CV, Corash L: Photochemical inactivation of pathogenic bacteria in human platelet concentrates. Blood 1994;83:2698-2706.

13 Tada-Oikawa S, Oikawa S, Kawanishi S: Role of ultraviolet A-induced oxidative DNA damage in apoptosis via loss of mitochondrial membrane potential and caspase- 3 activation. Biochem Biophys Res Commun 1998;247: 693-696.

14 Murphy S, Rebulla P, Bertolini F, et al: In vitro assessment of the quality of stored platelet concentrates. Transfus Med Rev 1994;8:29-36.
15 Rinder HM, Murphy M, Mitchell JG, et al: Progressive platelet activation with storage evidence for shortened survival of activated platelets after transfusion. Transfusion 1991; 31:409-414.

16 Holme S, Sweeney JD, Sawyer S, Elfath MD: The expression of P-selectin during collection, processing and storage of platelet concentrates: Relationship to loss of in vivo viability. Transfusion 1997;37:12-17.

17 Triulzi DJ, Kickler TS, Braine HG: Detection and significance of alpha granule membrane protein 140 expression on platelets collected by apheresis. Transfusion 1992;32:529-533.

18 Triulzi DT, Houston A, Kiss JE, Winkelstein A: The P-selectin epitope recognized by antiCD 62 on activated platelets does not correlate with platelet recovery. Transfusion 1994;34: $77 \mathrm{~S}$

19 Blajchman MA, Seugi AF, Hirsh J: Hemostatic function, survival, and membrane glycoprotein changes in young versus old rabbit platelets. $\mathrm{J}$ Clin Invest 1981;68:1289-1294.

20 Corash L, Behrman B, Rheinschmidt M, Wages D, Snyder E, Raife T, Kagen L, Baril L, Davis K, Metzel P, Walsh J, Smith D, Shafer S, Cimino G, Hei D, Tessman J, Lin L, Buchholz DH: Post-transfusion viability and tolerability of photochemically treated platelet concentrates (PC). (abstract 1171) Blood 1997;90:10.

21 Slichter SJ, Corash L, Grabowski M, LeBlanc R, Sedgwick J, Townsend-McCall D, Davis K, Behrman B, Rheinschmidt M, Metzel P, Lin L, Buchholz DH: Viability and hemostatic function of photochemically treated (PCT) platelets in thrombocytopenic patients. Blood 1999; 94(suppl 1):376a. 